\title{
Parametric Study of Factors Affecting Lateral Stability of a Public Transportation Vehicle
}

\author{
Vania Katherine Mulia ${ }^{1}$, Fitri Endrasari ${ }^{1}$, Djati Wibowo $^{1 *}$, Ibham Veza $^{2}$ \\ ${ }^{1}$ Mechanical Engineering Department, Faculty of Engineering and Technology, Sampoerna University, Indonesia \\ ${ }^{2}$ Faculty of Mechanical Engineering, Universiti Teknikal Malaysia Melaka, Malaysia \\ *Email: djati.wibowo@sampoernauniversity.ac.id
}

\begin{abstract}
The availability of public transport is one of the solutions to traffic congestion in Jakarta. Focusing on angkot, one of the public transport types in Jakarta, this study discusses a model and simulations to investigate several factors that affect its lateral stability. Those factors include rear tire inflation pressure, passenger configuration, velocity, and downhill inclination angle. The results show that the stability of an angkot is proportional to the rear tires cornering stiffness. It also has an indirect relationship with the passenger configuration within the angkot. Moreover, the stability of an angkot decreases as its velocity and the angle of the inclined road increase. In general, this study is expected to have a contribution to the development of public transport in Jakarta, especially angkot.
\end{abstract}

Keywords

Angkot; Cornering stiffness; Public transport; Stability

\section{Introduction}

Jakarta is the most populous city in Indonesia [1]. Jakarta's population has been increasing since 1951 with an annual increment of $1.35 \%$ [2]. By 2021, the population in Jakarta is estimated at $10,915,364$. This number of populations is in line with the economic growth within the city. However, it also has several consequences, including traffic congestion. In 2020, Indonesia's traffic index was ranked 31 from 416 cities in the world, with $36 \%$ of the congestion level [3]. This index shows that reducing traffic congestion is needed.

There are several ways to reduce traffic congestion. One of them is by providing public transport [4]. Besides alleviating traffic congestion, the cost of using public transport is less than the cost of using private cars or motorcycles. Moreover, when more people use public transport, fewer vehicles are used. Thus, fewer greenhouse gases are emitted [5]. Moreover, public transport can reduce the fatigue experienced by the users compared to traveling using private cars or motorcycles. However, one thing that must not be excluded from public transport is its safety.

In Jakarta, one of the most used public transport is angkot. Angkot is an abbreviation for angkutan kota or city transportation. It is a minivan with passenger seats that are being modified in such a way that it can fit up to 18 people. People use angkot for short-distance travel such as going to school, work, and so on. Since angkot is used by many people, the safety of angkot is seriously taken into account [6]. Besides the lack of safety riding, angkot is known to have poor lateral stability or, in short, stability. Much single-vehicle accident occurs on angkot because of its poor stability.

The stability of a vehicle is affected by internal and external factors. Internal factors include its dimension, center of gravity, and tire properties. Meanwhile, external factors include road conditions, weather, and so on. In October 2018, for example, a news report that an angkot had a single-vehicle accident in East Jakarta due to a tire leak [7]. Another news reported a singlevehicle accident of a vehicle happened at the sharply inclined road at Cipularang Highway [8], which shows that any vehicle has the potential of a single-vehicle accident on a sharply inclined road. See for more examples about single-accident of angkot in [9], [10]. These accidents show that a study on stability factors of an angkot is needed.

The stability of a vehicle is affected by the cornering stiffness of its tires, and the cornering stiffness is affected by the vertical load on it. When a vehicle moves on a curved path, the vertical force that acts on each tire changes. The difference between these forces might cause the vehicle to lose its stability. Several studies on the factors affecting the stability of a fourwheeled vehicle have been done. However, they are done under the assumptions of either flat road or rigid vehicle model. A study by Eunhyek et al. [11], for example, estimates the tire slip angle for various road conditions without tire-road information for vehicle stability control. Even though the road conditions are 
varied, this study assumes the tires as rigid bodies. Another study by Vladimir et al. [12] also analyzes the factor affecting the stability of a vehicle. This study focuses on how vehicle load affects driving characteristics. This study is done under the assumption that there is no lateral deformation on the tires and that the vehicle moves on a flat road. It concludes that vehicle load causes changes in the center of gravity position. In a real application, a vehicle's tires are not rigid. It can deform or inflate. Also, not all road surfaces are flat. There are times when a vehicle needs to move on an inclined path.

In this study, the effect of tire inflation pressure and vertical load towards cornering stiffness and vehicle stability are examined through simulation using MATLAB. Compared to the previous studies, this study considers a more realistic situation by employing the tires inflation pressure within the analysis. Moreover, this study also analyzes the effect of the road inclination angle on the stability of the angkot. Those analyses are done under several passenger configurations. This study is expected to be used to establish guidelines for the operation of angkot to prevent the single-vehicle accident.

\section{Methodology}

\subsection{Simple handling model of a vehicle}

To determine the stability of the vehicle, lateral dynamics analysis is applied to a vehicle to obtain a simple handling model. In deriving the simple handling model, the bicycle model is used to perform lateral dynamics analysis. The vehicle model can be seen in Figure 1, and the parameters used in the model are listed in Table 1.

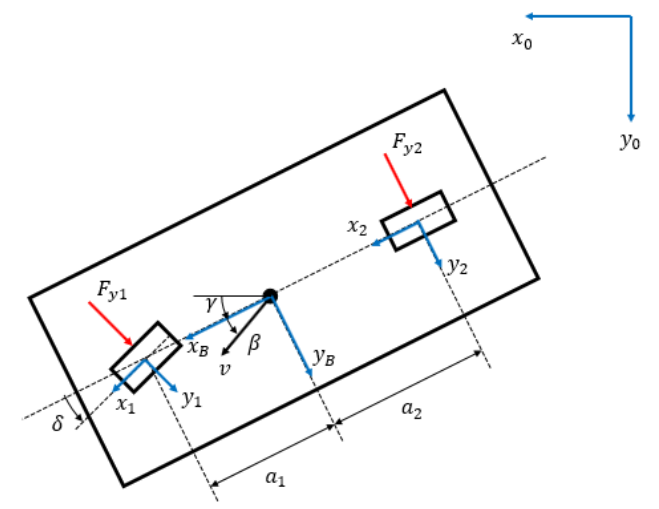

Figure 1 Bicycle model of vehicle.

In the modeling of the simple handling system, a smallangle approximation is applied to the yaw velocity of the vehicle $\dot{\gamma}$, the sideslip angle $\beta$, and the steering angle $\delta$. In addition, since the sideslip angle always labels the smaller angle between the velocity vector and the longitudinal vehicle axis, thus the approximation for longitudinal velocity becomes,

$$
v \sin \beta=|v| \beta
$$

Table 1 Parameters used in vehicle handling system modeling.

\begin{tabular}{|c|c|}
\hline Symbol & Description \\
\hline$\beta$ & Side-slip angle \\
\hline$\gamma$ & Yaw angle \\
\hline$\omega$ & Yaw rate \\
\hline$m$ & Vehicle mass \\
\hline$\Theta$ & $\begin{array}{l}\text { Vehicle mass moment of inertia about the vertical } \\
\text { axis }\end{array}$ \\
\hline$c_{s 1}$ & Cornering stiffness of the front tire \\
\hline$c_{s 2}$ & Cornering stiffness of the rear tire \\
\hline$a_{1}$ & $\begin{array}{l}\text { Distance between the center of mass and front tire } \\
\text { axle }\end{array}$ \\
\hline$a_{2}$ & $\begin{array}{l}\text { Distance between the center of mass and rear tire } \\
\text { axle }\end{array}$ \\
\hline$v$ & The velocity of the vehicle \\
\hline$\delta$ & Steering angle \\
\hline
\end{tabular}

Using the small-angle approximation, the equation of motion in the lateral direction becomes,

$$
m(v \dot{\gamma}+|v| \dot{\beta})=F_{y 1}+F_{y 2}
$$

and the angular motion becomes,

$$
\Theta \dot{\omega}=a_{1} F_{y 1}-a_{2} F_{y 2}
$$

where $\omega=\dot{\gamma}$. The tire lateral forces can be expressed as a linear function.

$$
F_{y}=c_{s} s_{y}
$$

where $s_{y}$ is the lateral slip. In general, the lateral slip can be expressed as,

$$
s_{y}=\frac{v_{y}}{v_{x}}
$$

where $v_{y}$ and $v_{x}$ are the lateral and longitudinal velocity of the tire relative to the vehicle. Since the front and rear tires create different angles with the vehicle's axis, the lateral slip must be defined for each tire. Using the small-angle approximation, the lateral slip of the front tire can be expressed as,

$$
s_{y 1}=-\beta-\frac{a_{1}}{|v|} \omega+\frac{v}{|v|} \delta
$$


and the lateral slip of the rear tire can be expressed as,

$$
s_{y 2}=-\beta+\frac{a_{2}}{|v|} \omega
$$

Thus, substituting Equations (6) and Equation (7) into Equation (4), the tire lateral force for each tire can be expressed as,

$$
\begin{aligned}
& F_{y 1}=c_{s 1}\left(-\beta-\frac{a_{1}}{|v|} \omega+\frac{v}{|v|} \delta\right) \\
& F_{y 2}=c_{s 2}\left(-\beta+\frac{a_{2}}{|v|} \omega\right)
\end{aligned}
$$

And finally, substituting Equation (8) and Equation (9) into Equation (2) and Equation (3) and rearranging the terms, two coupled but linear first-order differential equations can be found.

$$
\begin{gathered}
\dot{\beta}=\frac{c_{s 1}}{m|v|}\left(-\beta-\frac{a_{1}}{|v|} \omega+\frac{v}{|v|} \delta\right) \\
+\frac{c_{s 2}}{m|v|}\left(-\beta+\frac{a_{2}}{|v|} \omega\right)-\frac{v}{|v|} \omega \\
\dot{\omega}=\frac{a_{1} c_{s 1}}{\Theta}\left(-\beta-\frac{a_{1}}{|v|} \omega+\frac{v}{|v|} \delta\right) \\
-\frac{a_{2} c_{s 2}}{\Theta}\left(-\beta+\frac{a_{2}}{|v|} \omega\right)
\end{gathered}
$$

Equation (10) and Equation (11) can also be written in the form of a state-space equation.

$$
\dot{x}=A x+B u
$$

Where,

$$
\begin{aligned}
x & =\left[\begin{array}{l}
\beta \\
\omega
\end{array}\right] \\
A & =\left[\begin{array}{cc}
-\frac{c_{s 1}+c_{s 2}}{m|v|} & \frac{a_{2} c_{s 2}-a_{1} c_{s 1}}{m|v||v|}-\frac{v}{|v|} \\
\frac{a_{2} c_{s 2}-a_{1} c_{s 1}}{\Theta} & -\frac{a_{1}^{2} c_{s 1}+a_{2}^{2} c_{s 2}}{\Theta|v|}
\end{array}\right] \\
B & =\left[\begin{array}{ll}
\frac{v}{|v|} \frac{c_{s 1}}{m|v|} \\
\frac{v}{|v|} \frac{a_{1} c_{s 1}}{\Theta}
\end{array}\right]
\end{aligned}
$$

$$
u=[\delta]
$$

Furthermore, the tire cornering stiffness $c_{S 1}$ and $c_{S 2}$ can be expressed as a linear function of the vertical load $F_{Z}$ on each tire.

$$
\begin{aligned}
& c_{s 1}=c_{s}^{\text {lin }} F_{z 1} \\
& c_{s 2}=c_{s}^{\text {lin }} F_{z 2}
\end{aligned}
$$

where $c_{S}^{\text {lin }}$ in a constant depending on the tire properties and characteristics and $F_{z 1}$ and $F_{z 2}$ are the vertical road on the front and rear tire, respectively, which can be found by applying the moment equation of equilibrium at the vehicle's center of gravity about the lateral axis.

\subsection{Simulation using MATLAB}

To determine the stability of the vehicle, the state matrix $A$ is considered. To demonstrate the stability of the vehicle, simulations are done in MATLAB software, with parameters taken from a model of public transportation in Jakarta (angkot) with three passenger configurations:

1. Empty vehicle,

2. Half-full of passengers concentrated on the front part of the vehicle, and

3. Half-full of passengers concentrated on the back part of the vehicle.

The parameter values for the simulation are listed in Table 2.

Table 2 Parameters used in the simulation.

\begin{tabular}{cccc}
\hline Parameter & $\begin{array}{c}\text { Empty } \\
\text { Vehicle }\end{array}$ & $\begin{array}{c}\text { Half-full, front- } \\
\text { concentrated }\end{array}$ & $\begin{array}{c}\text { Half-full, back- } \\
\text { concentrated }\end{array}$ \\
\hline$m$ & $1600 \mathrm{~kg}$ & $2090 \mathrm{~kg}$ & $2090 \mathrm{~kg}$ \\
$\Theta$ & $\begin{array}{c}1058.57 \\
\mathrm{~kg} \cdot \mathrm{m}^{2}\end{array}$ & $1237.85 \mathrm{~kg} \cdot \mathrm{m}^{2}$ & $1758.19 \mathrm{~kg} \cdot \mathrm{m}^{2}$ \\
$c_{s 1}$ & \multicolumn{3}{c}{ Constant depending on $F_{z 1}$} \\
$c_{s 2}$ & Varied based on linear interpolation from (3) \\
$a_{1}$ & $1.2 \mathrm{~m}$ & $1.3 \mathrm{~m}$ & $1.44 \mathrm{~m}$ \\
$a_{2}$ & $1.45 \mathrm{~m}$ & $1.35 \mathrm{~m}$ & $1.21 \mathrm{~m}$ \\
$\delta$ & \multicolumn{3}{c}{$0.5 \mathrm{rad}$} \\
\hline
\end{tabular}

The stability of the vehicle depends on the cornering stiffness of each tire $c_{s 1}$ and $c_{s 2}$ and the velocity of the vehicle $v$. An unstable condition happens when the real part of one of the eigenvalues of matrix A in Equation (12) is positive [13]. When a high-speed approximation is applied for forwarding driving (i.e., $v>0$ ), the system is unstable if [13].

$$
\begin{aligned}
& a_{2} c_{s 2}-a_{1} c_{s 1}<0 \\
& a_{2} c_{s 2}<a_{1} c_{s 1}
\end{aligned}
$$


Which can happen in many physical phenomena that affect the value of the cornering stiffness of each tire.

The cornering stiffness depends on many variables of the tire conditions, such as the size, type, and treads [14]. Among all factors, tire inflation pressure and the vertical load become the main factors affecting the cornering stiffness [15]. Tire inflation pressure affects the length of the contact patch with the road and vertical tire stiffness. Higher inflation pressure is associated with higher vertical stiffness, which is proportional to the cornering stiffness. However, it also reduces the length of the contact patch with the road [16], [17]. Thus, the effect of tire inflation pressure towards cornering stiffness may vary depending on other factors such as vertical tire load [17]. To simulate this effect, it is assumed that the cornering stiffness of the rear tire is reduced by an arbitrary percentage. Another big factor that affects the cornering stiffness is the vertical load. In small slip conditions, cornering stiffness is directly proportional to the vertical load [13], [14]. When the vehicle with identical tires is moving on a horizontal road, it will be steering neutrally on a horizontal road [13]. However, if the vehicle is moving on an inclined road, the misalignment between the vertical load on each tire and the vehicle's weight results in the weight distributed unevenly between the tires. Thus, one of the tire's cornering stiffness will be much greater than the other one, possibly causing instability of the vehicle.

\section{$3 \quad$ Results and Discussions}

\subsection{Effect of rear tire inflation pressure and passenger configuration towards stability on flat road}

In this simulation, the effect of tire inflation pressure is indicated by varying multiplying factors of the tire cornering stiffness, which are applied to the rear tire (varying $c_{s 2}$ ) to test for possibilities of instability. The simulation is carried under the condition of a flat road with a constant velocity of $60 \mathrm{~km} / \mathrm{h}$ (approximately $16.67 \mathrm{~m} / \mathrm{s}$ ). In addition, the effect of passenger configuration is also investigated by doing the simulation in three different passenger configurations. The simulation results for all three configurations can be seen in Figure 2, Figure 3, and Figure 4.
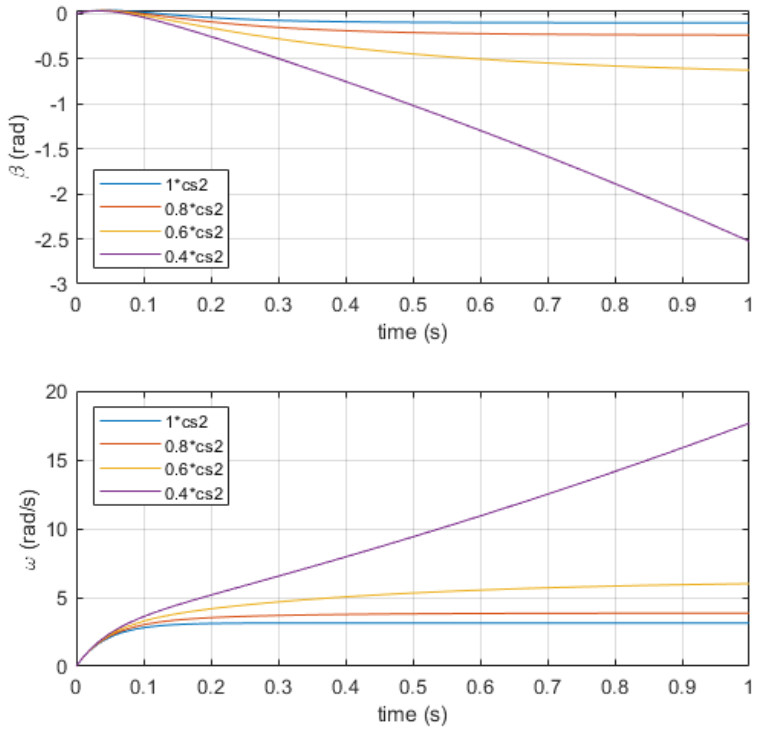

Figure 2 Simulation result for the empty vehicle on a flat road with various rear tire cornering stiffness.

From Figure 2-Figure 4, it can be seen that for all passenger configurations, the stability of the vehicle reduces when $c_{s 2}$ is reduced. In these simulations, all configurations become unstable when at $0.4 c_{s 2}$, indicated by the plots not reaching a steady state condition. Furthermore, the stability can be checked by the eigenvalues of the state matrix, and the values can be seen in Table 3 for a flat horizontal road condition at $60 \mathrm{~km} / \mathrm{h}$. For all passenger configurations, the first eigenvalue shifts towards a positive real value indicating less stability - as $c_{s 2}$ decreases, and at $0.4 c_{s 2}$, one of the eigenvalues has a positive real value and thus the system becomes unstable.
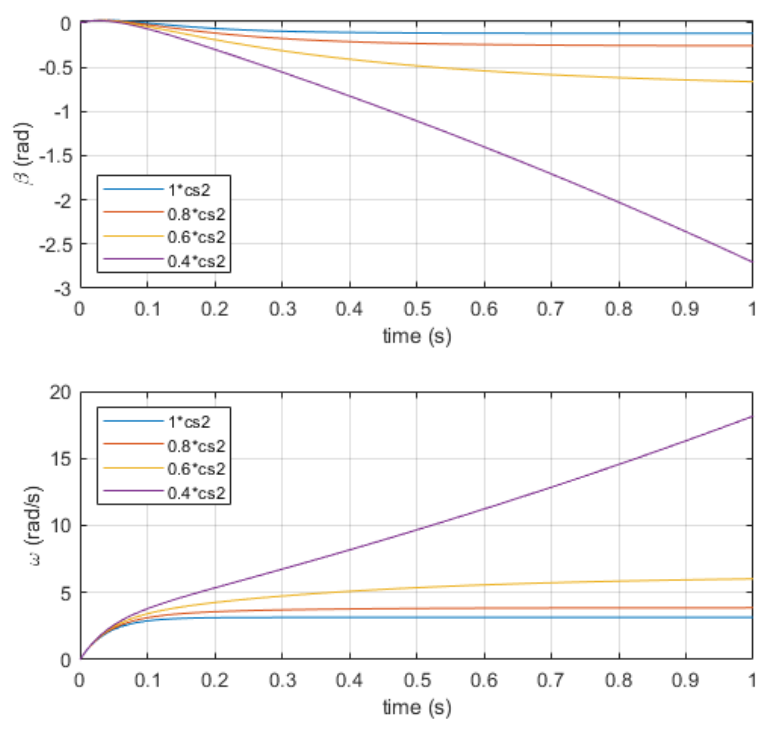

Figure 3 Simulation result for a half-full, front-concentrated vehicle on a flat road with various rear tire cornering stiffness. 

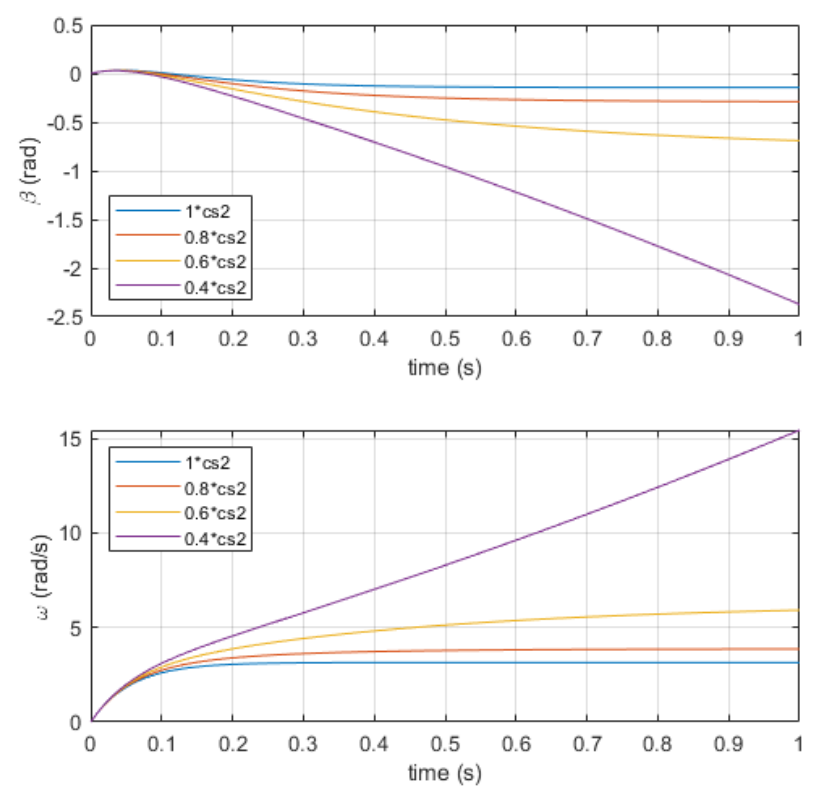

Figure 4 Simulation of a half-full, back-concentrated vehicle on a flat road with various rear tire cornering stiffness.

Table 3 Eigenvalues of the state matrix for a flat road condition with various rear cornering stiffness.

\begin{tabular}{cccc}
\hline $\begin{array}{c}\text { Rear tire } \\
\text { cornering } \\
\text { stiffness }\end{array}$ & $\begin{array}{c}\text { Empty } \\
\text { vehicle }\end{array}$ & $\begin{array}{c}\text { Hassenger configuration } \\
\text { concentrated }\end{array}$ & $\begin{array}{c}\text { Half-full, back- } \\
\text { concentrated }\end{array}$ \\
\hline \multirow{2}{*}{$c_{s 2}$} & -8.43 & -8.43 & -8.43 \\
& -22.18 & -24.99 & -17.55 \\
$0.8 c_{s 2}$ & -5.57 & -5.61 & -5.31 \\
& -21.85 & -24.44 & -18.16 \\
$0.6 c_{s 2}$ & -2.61 & -2.65 & -2.41 \\
& -21.62 & -24.04 & -18.54 \\
$0.4 c_{s 2}$ & 0.41 & 0.42 & 0.37 \\
& -21.46 & -23.73 & -18.80 \\
\hline
\end{tabular}

Although all three configurations exhibit the same trend with decreasing rear tire cornering stiffness, there are differences in eigenvalues between the three configurations. With a rear tire cornering stiffness of $0.6 c_{s 2}$ and above, the half-full back-concentrated configuration has eigenvalues closest to the positive real value, while the front-concentrated configuration has eigenvalues furthest from the positive real value. At the unstable condition $\left(0.4 c_{s 2}\right)$, the eigenvalues comparison is in fact reversed. the eigenvalues comparison is in fact reversed. Compared with the location of the center of mass from Table 2, it can be concluded that the effect of passenger configuration towards stability is not easily defined as proportional or inversely proportional. Instead, the simulation result can be justified by considering the inequality in Equation (19). By moving the center of mass backward, although it reduces $a_{2}$, it also increases $c_{s 2}$ since $c_{s 2}$ depends on the vertical load distribution on both wheels. Thus, there must be an optimal location for the center of gravity in order to get the best stability.

\subsection{Effect of road inclination angle for a vehicle going downhill}

The effect of road inclination angle for a vehicle going downhill is investigated by simulating the vehicle handling system with the empty vehicle configuration driving at a velocity of $60 \mathrm{~km} / \mathrm{h}$. The vehicle is simulated with $5^{\circ}$ and $10^{\circ}$ road inclination angles and with the same rear tire cornering stiffness values as those in Section 3.1. The stability between those two angles and the flat road condition (obtained from Section 3.1) are compared based on the plots and eigenvalues. The simulation results can be seen in Figure 5 and Figure 6.

Comparing between Figure 2, Figure 5, and Figure 6, even though the overall trend of the plots is similar, at $0.4 c_{s 2}$, the values of both side slip angle $(\beta)$ and yaw rate $(\omega)$ reach greater absolute values much quicker as the road inclination angle increases. This is an indication that the stability reduces as the inclination angle increases (i.e., the downhill road becomes steeper). Another good indication of the stability is the eigenvalues, which can be seen in Table 4. It can be seen that for the same value or rear tire cornering stiffness, one of the eigenvalues shifts towards positive real value as the road inclination angle increases, and at $0.4 c_{s 2}$, the positive real eigenvalue increases in value as the road inclination angle increases. Thus, it can be concluded that the vehicle stability reduces with greater road inclination angle when going downhill.
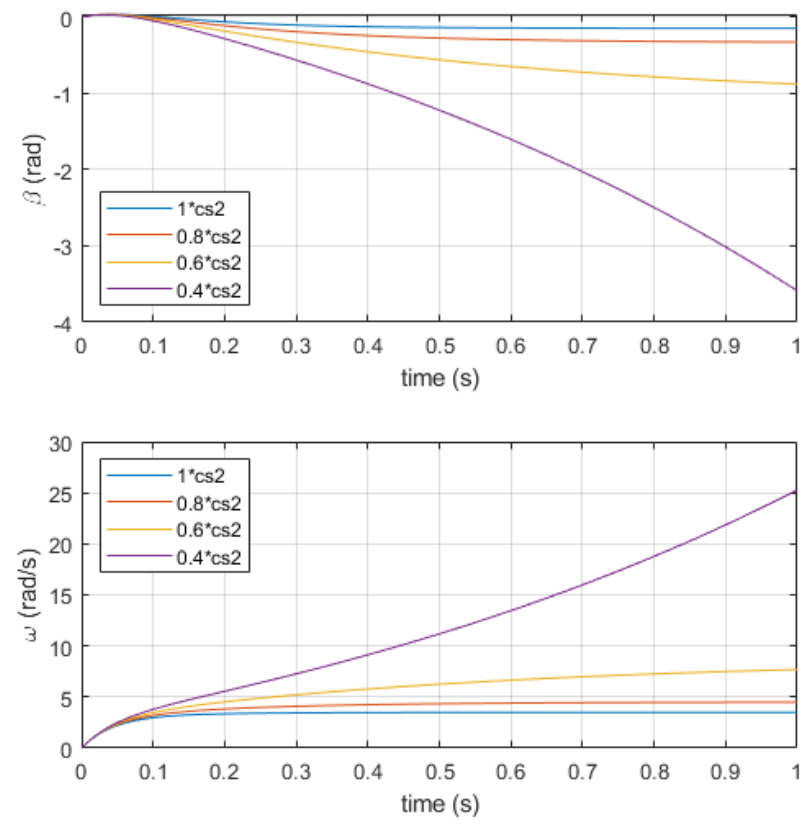

Figure 5 Simulation results on an empty vehicle going downhill $5^{\circ}, 60 \mathrm{~km} / \mathrm{h}$ with various rear tire cornering stiffness. 

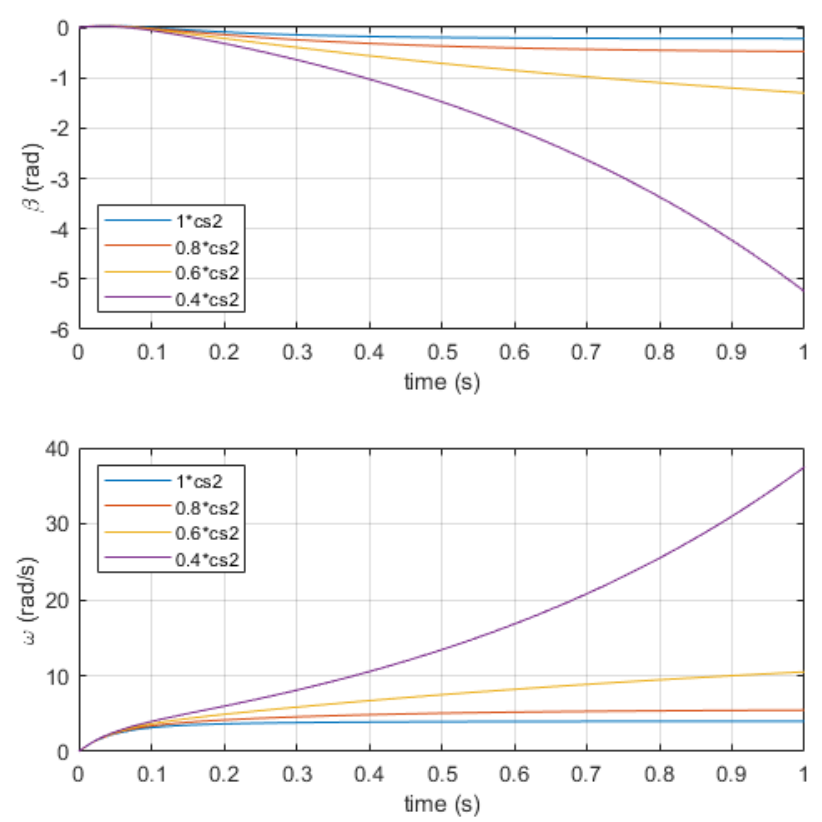

Figure 6 Simulation results on an empty vehicle going downhill $10^{\circ}, 60 \mathrm{~km} / \mathrm{h}$ with various rear tire cornering stiffness.

Table 4 Eigenvalues of the state matrix for empty vehicle configuration going downhill with various angles.

\begin{tabular}{|c|c|c|c|}
\hline \multirow[b]{2}{*}{$\begin{array}{c}\text { Rear tire } \\
\text { cornering } \\
\text { stiffness }\end{array}$} & \multicolumn{3}{|c|}{ Road Inclination Angle } \\
\hline & $\begin{array}{c}0^{\circ} \\
\text { (Flat } \\
\text { horizontal } \\
\text { road) }\end{array}$ & $5^{\circ}$ & $10^{\circ}$ \\
\hline$c_{s 2}$ & $\begin{array}{l}-8.43 \\
-22.18\end{array}$ & $\begin{array}{c}-7.1 \\
-23.13\end{array}$ & $\begin{array}{c}-5.74 \\
-23.86\end{array}$ \\
\hline $0.8 c_{s 2}$ & $\begin{array}{c}-5.57 \\
-21.85\end{array}$ & $\begin{array}{c}-4.46 \\
-22.81\end{array}$ & $\begin{array}{c}-3.34 \\
-23.58\end{array}$ \\
\hline $0.6 c_{s 2}$ & $\begin{array}{l}-2.61 \\
-21.62\end{array}$ & $\begin{array}{c}-1.75 \\
-22.58\end{array}$ & $\begin{array}{c}-0.88 \\
-23.36\end{array}$ \\
\hline $0.4 c_{s 2}$ & $\begin{array}{c}0.41 \\
-21.46 \\
\end{array}$ & $\begin{array}{c}1.02 \\
-22.4 \\
\end{array}$ & $\begin{array}{c}1.62 \\
-23.18 \\
\end{array}$ \\
\hline
\end{tabular}

\subsection{Effect of velocity and passenger configuration on a downhill road}

The effect of velocity and passenger configuration on a downhill road is investigated by simulating the vehicle handling system in two different road inclination angles with two different velocities and various passenger configurations. The simulation is done on $5^{\circ}$ and $10^{\circ}$ road inclination angle with velocities of $30 \mathrm{~km} / \mathrm{h}$ (approximately $8.33 \mathrm{~m} / \mathrm{s}$ ) and $60 \mathrm{~km} / \mathrm{h}(16.67 \mathrm{~m} / \mathrm{s})$. The simulation results can be seen in Figure 7-Figure 10. The effect of velocity can be observed by comparing the simulation results with the same passenger configuration and inclination angle. The effect of passenger configuration can be observed by comparing the plot for all three different passenger configurations in each inclination angle and velocity.
The simulation results show a variation of trends between $30 \mathrm{~km} / \mathrm{h}$ and $60 \mathrm{~km} / \mathrm{h}$. At $60 \mathrm{~km} / \mathrm{h}$, the system exhibits a non-minimum phase behavior. Meanwhile, the stability can be evaluated by looking at the eigenvalues, as seen in Table 5. It can be seen that for all configurations and in all angles, the eigenvalues shift more towards positive real value as the velocity increases. Thus, the vehicle stability decreases with increasing velocity. As for the effect of passenger configuration, the eigenvalue comparison between the three configurations is similar to that on a flat road (Section 3.1).

Table 5 Eigenvalues of the state matrix for various vehicle configurations going downhill.

\begin{tabular}{|c|c|c|c|c|}
\hline \multirow[b]{2}{*}{$\begin{array}{c}\text { Road } \\
\text { inclination } \\
\text { angle }\end{array}$} & \multirow[b]{2}{*}{ Velocity } & \multicolumn{3}{|c|}{ Passenger configuration } \\
\hline & & $\begin{array}{l}\text { Empty } \\
\text { vehicle }\end{array}$ & $\begin{array}{c}\text { Half-full, } \\
\text { front- } \\
\text { concentrated }\end{array}$ & $\begin{array}{c}\text { Half-full, } \\
\text { back- } \\
\text { concentrated }\end{array}$ \\
\hline & $30 \mathrm{~km} / \mathrm{h}$ & $\begin{array}{l}-16.03 \\
-44.46\end{array}$ & $\begin{array}{c}-16.1 \\
-50.43\end{array}$ & $\begin{array}{l}-15.94 \\
-36.27\end{array}$ \\
\hline 5 & $60 \mathrm{~km} / \mathrm{h}$ & $\begin{array}{c}-7.1 \\
-23.13\end{array}$ & $\begin{array}{l}-7.19 \\
-26.06\end{array}$ & $\begin{array}{l}-6.98 \\
-19.1\end{array}$ \\
\hline $10^{\circ}$ & $30 \mathrm{~km} / \mathrm{h}$ & $\begin{array}{c}-14.84 \\
-44.40 \\
-5.74 \\
-23.86\end{array}$ & $\begin{array}{l}-15 \\
-50.64 \\
-5.91 \\
-26.89\end{array}$ & $\begin{array}{c}-14.73 \\
-37.29 \\
-5.68 \\
-20.31\end{array}$ \\
\hline
\end{tabular}
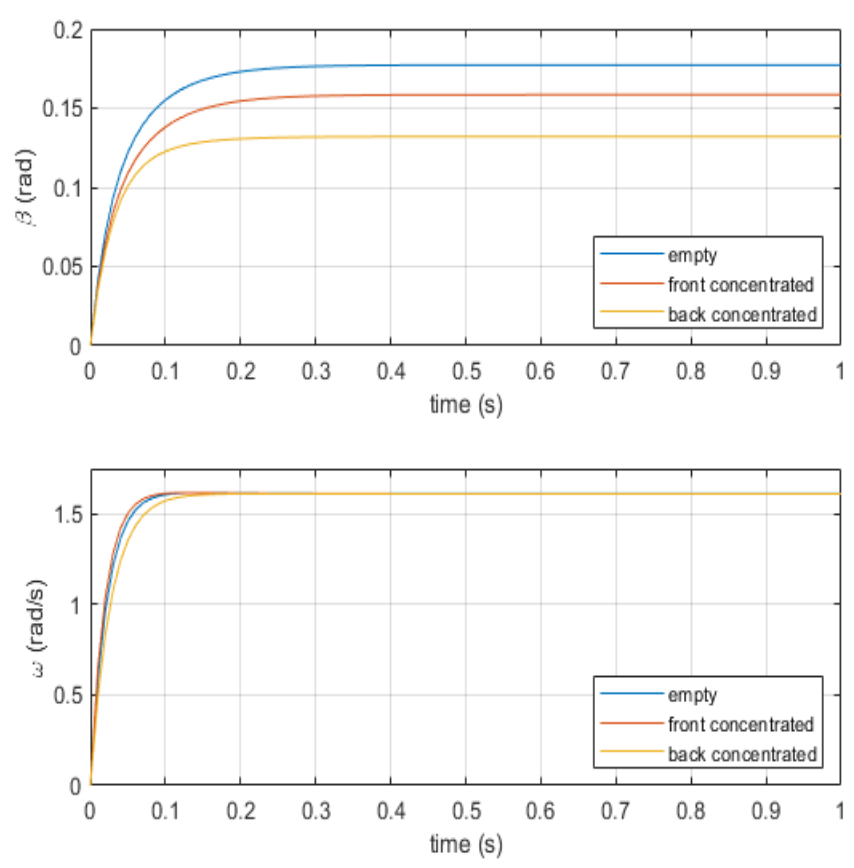

Figure 7 Simulation results of the vehicle going downhill $5^{\circ}$, $30 \mathrm{~km} / \mathrm{h}$. 

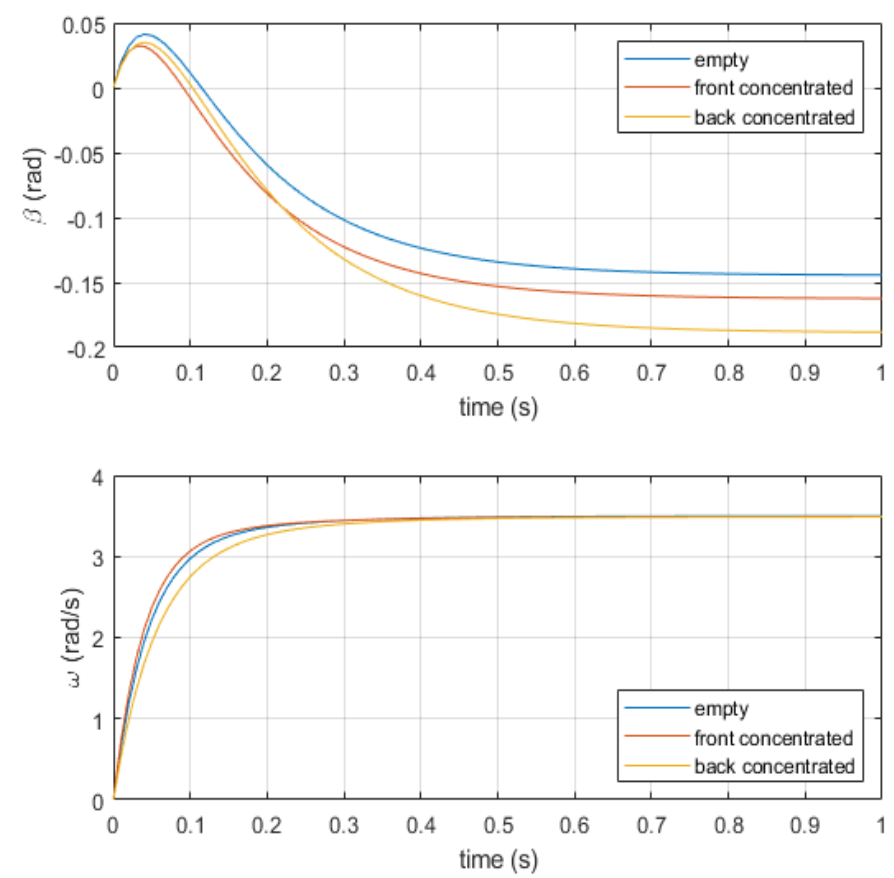

Figure 8 Simulation results of the vehicle going downhill $5^{\circ}$, $60 \mathrm{~km} / \mathrm{h}$.
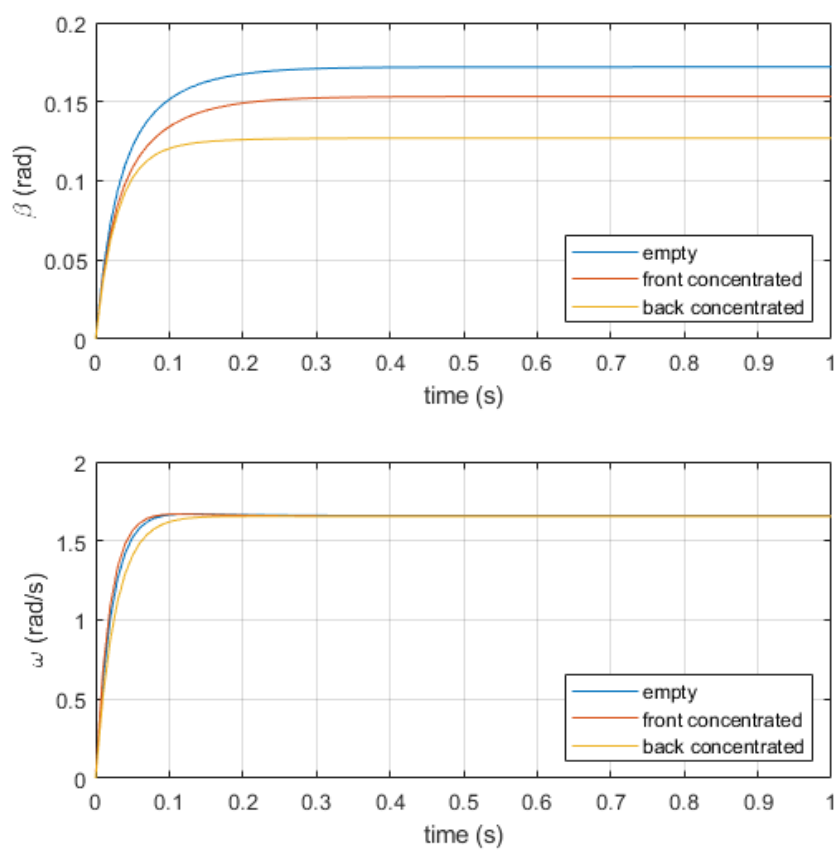

Figure 9 Simulation results of the vehicle going downhill $10^{\circ}, 30 \mathrm{~km} / \mathrm{h}$.
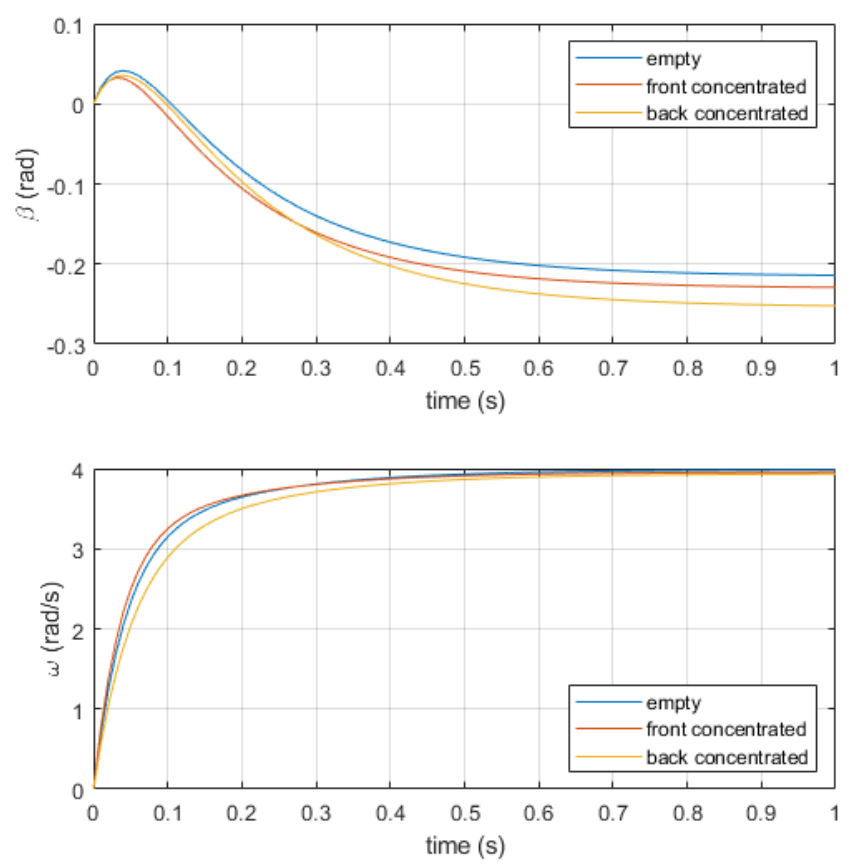

Figure 10 Simulation results of the vehicle going downhill $10^{\circ}, 60 \mathrm{~km} / \mathrm{h}$.

\section{Conclusion}

In this study, simulations are done in MATLAB to investigate the effect of various factors on stability. Those factors are rear tire inflation pressure, passenger configuration, velocity, and downhill inclination angle. Tire inflation pressure affects the cornering stiffness of the tire, represented by a multiplying factor in the rear tire cornering stiffness $c_{S 2}$. Meanwhile, passenger configuration and downhill inclination angle affect the distribution of vertical load on the tires, which also affects the cornering stiffness. The stability is observed from the plot of sideslip angle $\beta$ and yaw rate $\omega$ as well as the eigenvalues of the state matrix A.

Simulation shows that, in general, the stability of a vehicle reduces as the rear tire cornering stiffness reduces. The passenger configuration also slightly affects the stability of the vehicle, although the relationship is not really straightforward. There should exist an optimum location of the center of mass to obtain better stability. For a vehicle going downhill, the stability reduces as the road inclination angle increases. The stability is also affected by the velocity of the vehicle, which may also cause the system to change between the minimum and non-minimum phase systems. In general, the stability of the vehicle reduces as the velocity increases. 


\section{References}

[1] Statista Research Department, "Indonesia - 10 Largest Cities," 2015. [Online]. Available: https://www.statista.com/statistics/319196/largest-cities-inindonesia/\#statisticContainer. [Accessed: 19-Oct-2021].

[2] World Population Review, "Jakarta Population 2021," 2021. [Online]. Available: https://worldpopulationreview.com/world-cities/jakartapopulation. [Accessed: 19-Oct-2021].

[3] TomTom International, “Traffic Index 2020," 2020. [Online]. Available: https://www.tomtom.com/en_gb/traffic-index/ranking/. [Accessed: 19-Oct-2021].

[4] Smarter Cambridge Transport, "Reducing Traffic Congestion and Pollution in Urban Areas," 2016. [Online]. Available: https://www.smartertransport.uk/smartercambridge-transport-urban-congestion-enquiry/. [Accessed: 19-Oct-2021].

[5] Kansas City Area Transportation Authority, "Environmental Benefits of Public Transit." [Online]. Available: https://www.kcata.org/about_kcata/entries/environmental_ benefits_of_public_transit. [Äccessed: 19-Oct-2021].

[6] A. Ramadhayanti, "Pengaruh Pengguna Transportasi Berkelanjutan Dan Displin Berlalu Lintas Terhadap Dampak Tingkat Keselamatan Berkendara (Safety Riding) Dalam Studi kasus Penumpang Angkutan Umum M.19 Kranji (Bekasi)-PGC (Cililitan)," J. Kaji. Ilm. Univ. Bhayangkara, vol. 18, no. 1, 2018.

[7] R. Atriana, "Leaky Tires, Causes Angkots Bring Dogs Overturned on Rawamangun Toll Road," Oct. 2018. [Online]. Available: https://news.detik.com/berita/d4245605/ban-bocor-penyebab-angkot-bawa-anjingterguling-di-tol-rawamangun. [Accessed: 19-Oct-2021].

[8] Y. D. Damaledo, "Accident List on Cipularang Toll Road from 2011 to 2019," Sep. 2019. [Online]. Available: https://tirto.id/daftar-kecelakaan-di-tol-cipularang-dari2011-hingga-2019-ehpx. [Accessed: 19-Oct-2021].

[9] S. Alamsyah, "Caught in an obscene manner, public transportation driver panics until he hits a security guard in
Sukabumi," Sep. 2021. [Online]. Available: https://news.detik.com/berita/d-5714185/terpergok-mesumsopir-angkot-panik-hingga-tabrak-satpam-di-sukabumi.

[Accessed: 19-Oct-2021].

[10] Dewantoro, "Angkot Speeds Then Overturns, 2 Passengers Killed, 3 Seriously Injured, Driver Runs," Jan. 2021. [Online]. Available: https://regional.kompas.com/read/2021/01/31/17104641/an gkot-ngebut-lalu-terbalik-2-penumpang-tewas-3-lukaserius-sopir-kabur. [Accessed: 19-Oct-2021].

[11] E. Joa, K. Yi, and Y. Hyun, "Estimation of the tire slip angle under various road conditions without tire-road information for vehicle stability control," Control Eng. Pract., vol. 86, pp. 129-143, 2019, doi: https://doi.org/10.1016/j.conengprac.2019.03.005.

[12] V. Rievaj, J. Vrábel, F. Synák, and L. Bartuška, "The Effects of Vehicle Load on Driving Characteristics," Adv. Sci. Technol. Res. J., vol. 12, no. 1, pp. 142-149, 2018, doi: 10.12913/22998624/80896.

[13] G. Rill, "Vehicle Dynamics Lecture Notes," Fachhochschule Regensbg. Regensburg, Ger., p. 39, 2006.

[14] G. S. Vorotović, B. B. Rakicević, S. R. Mitić, and D. D. Stamenković, "Determination of cornering stiffness through integration of a mathematical model and real vehicle exploitation parameters," FME Trans., vol. 41, no. 1, pp. 66-71, 2013.

[15] Z. El-Sayegh and M. El-Gindy, "Cornering characteristics of a truck tire on wet surface using finite element analysis and smoothed-particle hydrodynamics," Int. J. Dyn. Control 2018 64, vol. 6, no. 4, pp. 1567-1576, Feb. 2018, doi: 10.1007/S40435-018-0403-5.

[16] A. Strigel, U. Peckelsen, H.-J. Unrau, and F. Gauterin, "Estimation of feasible ranges of functional tire characteristics based on tire dimension, inflation pressure, and wheel load," Proc. Inst. Mech. Eng. Part D J. Automob. Eng., vol. 233, no. 14, pp. 3700-3706, Feb. 2019, doi: 10.1177/0954407019831575.

[17] K. B. Singh, "Vehicle sideslip angle estimation based on tire model adaptation," Electron., vol. 8, no. 2, pp. 1-24, 2019, doi: 10.3390/electronics8020199. 